\title{
Drones provide spatial and volumetric data to deliver new insights into microclimate modelling
}

\author{
James P. Duffy (D) Karen Anderson • Dominic Fawcett • Robin J. Curtis • \\ Ilya M. D. Maclean
}

Received: 9 July 2020/Accepted: 15 December 2020/Published online: 21 January 2021

(C) The Author(s) 2021

\begin{abstract}
Context Microclimate (fine-scale temperature variability within metres of Earth's surface) is highly influential on terrestrial organisms' ability to survive and function. Understanding how such local climatic conditions vary is challenging to measure at adequate spatio-temporal resolution. Microclimate models provide the means to address this limitation, but require as inputs, measurements, or estimations of multiple environmental variables that describe vegetation and terrain variation.

Objectives To describe the key components of microclimate models and their associated environmental parameters. To explore the potential of drones to provide scale relevant data to measure such environmental parameters.

Methods We explain how drone-mounted sensors can provide relevant data in the context of alternative remote sensing products. We provide examples of how direct micro-meteorological measurements can be made with drones. We show how drone-derived data can be incorporated into 3-dimensional radiative transfer models, by providing a realistic representation of the landscape with which to model the interaction of solar energy with vegetation.
\end{abstract}

J. P. Duffy $(\bowtie) \cdot$ K. Anderson · D. Fawcett .

R. J. Curtis · I. M. D. Maclean

Environment and Sustainability Institute, University of Exeter, Penryn Campus, Penryn, Cornwall TR10 9FE, UK

e-mail: james.philip.duffy@ gmail.com
Results We found that for some environmental parameters (i.e. topography and canopy height), data capture and processing techniques are already established, enabling the production of suitable data for microclimate models. For other parameters such as leaf size, techniques are still novel but show promise. For most parameters, combining spatial landscape characterization from drone data and ancillary data from lab and field studies will be a productive way to create inputs at relevant spatio-temporal scales.

Conclusions Drones provide an exciting opportunity to quantify landscape structure and heterogeneity at fine resolution which are in turn scale-appropriate to deliver new microclimate insights.

Keywords Climate $\cdot$ UAV $\cdot$ Radiation $\cdot$ Vegetation structure $\cdot$ Temperature $\cdot$ Topography

\section{Introduction}

Almost all terrestrial organisms are limited in what they do and where they persist by the temperature and humidity of the physical environment in which they reside. However, many studies investigating the relationships between species and climatic conditions use coarse spatial resolution datasets that ultimately bear little resemblance to conditions that organisms experience in the wild (Potter et al. 2013). Heterogeneous landscapes with highly spatially variable 
temperature and water availability are influenced by local terrain, vegetation and soil at fine (i.e. centimetre) scales. Additionally, microclimate is an important driver of the landscape-scale distribution of species, and should therefore be incorporated in relevant analyses (i.e. species distribution models; Lembrechts et al. 2019)). Thus, to investigate the direct links between climate and the physiology, behaviour, distribution and abundance of organisms, fine spatial and temporal resolution climate data are required (Kearney et al. 2012). In the face of climatic change on a global scale, an understanding is required of how microclimatic conditions mediate macro-climatic responses (Pincebourde et al. 2016). Also, microclimatic heterogeneity arising from landscape topography, can provide microrefugia for species facing environmental change in a warming world (Suggitt et al. 2018).

Remote sensing is now an established method for obtaining data for use in ecological research and monitoring (Pettorelli et al. 2015). Zellweger et al. (2019) provide insight into the remote sensing methodologies that have advanced and also have the potential to advance microclimate modelling. These include airborne Light Detection and Ranging (LiDAR; (Vierling et al. 2008), aerial photography, Terrestrial Laser Scanning (TLS; Ehbrecht et al. 2017), hyperspectral and thermal infra-red sensing. Lightweight drones (sub-7 kg in weight; mentioned briefly in the review by Zellweger et al. (2019)), and platforms such as balloons and kites (hereafter proximal sensing platforms) have increasingly established themselves as a means by which to gather spatial data. However, an exploration of what exactly to do with these data within microclimate research, once captured, remains lacking. A key hindrance to progress has been moving from detailed measures of the $3 \mathrm{D}$ structure of terrestrial ecosystems or thermal composition of landscapes at the time of data capture, to realistic measures of temperature and or humidity in time and space. To achieve this, models that predict the spatio-temporal dynamics of microclimates are needed.

The affordability and ease-of-use of drones have made them a democratising technological advance giving researchers and environmental stakeholders a self-service opportunity to capture data (Duffy et al. 2018). Lightweight drones with integrated cameras can be acquired for $<£ 1000$ and can be operated with freely available software after a few hours of practice and without requirement for specific training. As with alternative remote sensing approaches, processing can be a time-consuming process. With drones this is due to the potential to capture large volumes of data in a short period of time. Their flexible design and the ease with which a range of sensors and payloads can be attached make them ideally suited to capturing the data required to drive microclimate models. The timing of flights (i.e. data capture) can be tailored to deliver insights during events specifically important in understanding microclimate (e.g. leafing/senescence; Klosterman and Richardson 2017). Here we explore the opportunities and limitations of drone-based data capture with specific emphasis on how such data can be utilised once collected. Microclimate models have a long history of application in agricultural and forest science (i.e. MacHattie and McCormack 1961; Allen et al. 1976), but have yet to be readily adopted by biologists, at least in part because they have been primarily applied to relatively homogeneous environments such as crop fields, where in situ measurement of the required vegetation structure parameters is practical. Moreover, in many instances, the focus of research has been the nature of physical processes within microclimatic variation, such as the characteristics of turbulence within crop and forest canopies (Raupach et al. 1996; Finnigan 2000). Biologists are usually more interested in the application of the microclimatic data and often require spatial data from heterogeneous environments, and drones provide an ideal means by which the required vegetation structure parameters can be mapped in space. To date, applications of drones in research on microclimate include thermography of potato fields with implications for pest dynamics (Faye et al. 2016), thermal characterization of forest canopies (Webster et al. 2018) and quantifying the effect of artificial structures in agricultural landscapes on environmental conditions at the microclimate scale (Tucci et al. 2019).

The use of drones to acquire critical data for driving microclimate models remains largely unexplored. Here we briefly describe the principles of microclimate modelling (Microclimate modelling using energy balance equations section), with emphasis on the key determinants of microclimate. We then outline the parameters associated with such determinants (Table 1) and discuss the potential of drone acquired data to derive these parameters (Determining 
Table 1 Key components of microclimate and their associated environmental parameters

\begin{tabular}{llc}
\hline Microclimate parameter & Vegetation/terrain parameter & References \\
\hline $\begin{array}{l}\text { Canopy/ground surface parameters for } \\
\text { heat and momentum transfer above } \\
\text { canopies }\end{array}$ & Canopy height, plant area index & Maki (1975) and Shaw and \\
Pereira (1982) \\
$\begin{array}{l}\text { Within-canopy wind attenuation } \\
\text { coefficient }\end{array}$ & $\begin{array}{l}\text { Leaf area index, canopy height, leaf shape, distance } \\
\text { between leaves. Roughness length governing }\end{array}$ & Finnigan (2000, Goudriaan \\
& momentum transfer & 1977 and Raupach et al. \\
Leaf heat conductance & Leaf size & Cowan (1972) and Stokes \\
& et al. (2006) & Wong et al. (1979) \\
Stomatal conductance & Photosynthetic capacity of leaves, Leaf area index & Monteith and Unsworth \\
Reflected shortwave radiation & Reflectance of canopy/ground & (1990) \\
Campbell (1986) and & Kucharik et al. (1999) \\
Canopy radiation transmission & Leaf area index, leaf distribution angle, gap-size & Hay (1993)
\end{tabular}

Vegetation and terrain parameters are measurable properties of the natural environment that are required to calculate their associated microclimate parameters

vegetation and terrain parameters from drone-derived data section). Next, we discuss the potential ways in which drones can be used to directly measure microclimate (Topography section). Lastly, we provide an exemplar, showing how such data can be used for radiative transfer modelling, to obtain fine-resolution estimates of temperature (Canopy height section). Each of "Determining vegetation and terrain parameters from drone-derived data", "Topography" and "Canopy height" sections address different facets of the data required to drive microclimate models.

\section{Microclimate modelling using energy balance equations}

The development of mechanistic microclimate modelling has its origins rooted in work by Richardson (1922), who demonstrated the basic laws that govern wind and temperature profiles in the air immediately above vegetation. While much has been done to refine this work (Monin and Obukhov 1954; Goudriaan 1977; Monteith and Unsworth 1990; Campbell and Norman 1998) and make it accessible to biologists (see e.g.; Norman 1982; Monteith and Unsworth 1990; Campbell and Norman 1998; Bennie et al. 2008; Kearney and Porter 2017; Maclean et al. 2019), the basic equations governing heat, vapour and momentum transfer that influence these profiles are still widely used.

Understanding of the exchange of vapour and heat within canopies continues to be an area of active research. Initial work in the 1970's tried to relate observed wind and temperature profiles to local air flow using the same one-dimensional eddy diffusion theory that is still used for determining temperatures above canopy (see e.g. Goudriaan 1977). However, more recently, several authors (e.g. Finnigan 1985; Raupach 1989) have suggested that such theory is not necessarily applicable below canopy, where larger but infrequent winds are responsible for much of the heat and vapour exchange. Despite limitations in their theoretical applicability, it has been argued that they are still applicable in practice (see e.g. Monteith and Unsworth 1990), at least in terms of predicting how temperature and moisture profiles are influenced by canopy cover. The basic equations governing turbulent heat exchanges are thus still widely used. Here the temperature profile is described as follows:

$$
\left(T_{0}-T_{a i r}\right)=\left(r_{H R} / \rho C_{p}\right)\left(R_{n e t}-L-G\right)
$$

where $T_{O}$ is the aerodynamic temperature of the canopy at the height of the heat exchange surface, $T_{\text {air }}$ is the temperature of the air, $R_{n e t}$ is the net radiation flux at the surface, $L$ is the energy flux through the 
exchange of latent heat, $G$ is the energy flux to/from the soil, $r_{H R}$ is the resistance for the loss of sensible heat and $\rho C_{p}$ is the molar specific heat of air dependent on temperature. Each of the components of this equation are modified by properties of the microenvironment, and it is the variation in the microenvironment interacting with weather that drives variation in microclimate (Monteith and Unsworth 1990).

Many of the processes driving microclimatic variation operate at multiple and interacting scales. While proximal sensing cannot capture the minute microenvironments, such as the configuration of density of stomatal apertures on a leaf, or the precise location and angles of individual leaves, there are well-defined rules that relate these properties to those of vegetation and terrain that can be measured by sensors on-board drones. For example, a variant of the Beer-Lambert law can be used to relate canopy cover to radiation transmission with the inclusion of just two parameters describing leaf area and angle distribution (Campbell 1986). Similarly, an integration of this function over the entire canopy enables conductance for single leaves to be related to that of the entire canopy, based on simple rules that govern stomatal responses to photosynthetically active radiation (Kelliher et al. 1995). Below we summarise the key terrain and vegetation parameters that are needed to drive microclimate models (Table 1).

In the following sections we discuss the potential to characterise the key parameters defined in Table 1; using fine-grained geospatial data captured from drones. Further, we discuss the operations and complexities of integrating such data into microclimate models. Some parameters in Table 1 are grouped to enable more coherent and less repetitive discussion in the text. Following this we then discuss opportunities for drones to capture other measurements of microclimate. Given that radiation is a key determinant of microclimate, we also give an example of how drone data can be ingested into radiative transfer models to produce estimated radiation budgets, as influenced by habitat heterogeneity.

\section{Determining vegetation and terrain parameters from drone-derived data}

\section{Topography}

A quantitative measure of the topography of the landscape is needed to quantify how much sunlight is absorbed by an inclined ground surface and to determine wind sheltering effects (Maclean et al. 2019). Just above ground in very short vegetation and under calm, still conditions, where horizontal heat fluxes are minimal, or below ground, close to the surface where soil temperatures are highly sensitive to variation in radiation, spatial variation in slope, aspect and landcover type (e.g. vegetation/detritus/rock) over the scale of a few centimetres is likely to be important in determining microclimatic conditions (Monteith and Unsworth 1990). Thus, measurements at very fine spatial resolution can help to elucidate these variations (Fig. 1).

For microclimate studies, both digital terrain model (DTM) and digital surface model (DSM) products are required. DTMs are spatial grids that represent the variation in bare-Earth elevation of a landscape, whilst DSMs quantify the height of any objects which extrude from the Earth's surface. DSMs, and in some ecosystems DTMs, with sub-cm to mm spatial resolution can be readily obtained from drone-derived optical images through Structure-from-Motion MultiView Stereo (SfM-MVS) photogrammetry, which is now a mature data processing technique (Smith et al. 2016; Anderson et al. 2019) due to the increased affordability of high-performance software. The technique produces a 2.5-dimensional representation of an environment in the form of a spatially explicit point cloud or gridded raster product (usually a DSM unless the ground is unvegetated). Accompanying these standard products, are a point cloud, which describes spatially varying spectral reflectance values, a triangular mesh, built upon the point cloud, and spatial orthomosaic products (Fig. 2). A detailed review of the workflows involved in processing these data is beyond the scope of this paper, but see Smith et al. (2016) for an in-depth review of techniques, and Forsmoo et al. (2019) for a comparison of the available software options. A key consideration for those wishing to use such data is that creating datasets with SfM-MVS software can be a time-consuming process. Although SfM-MVS typically produces a DSM, in 

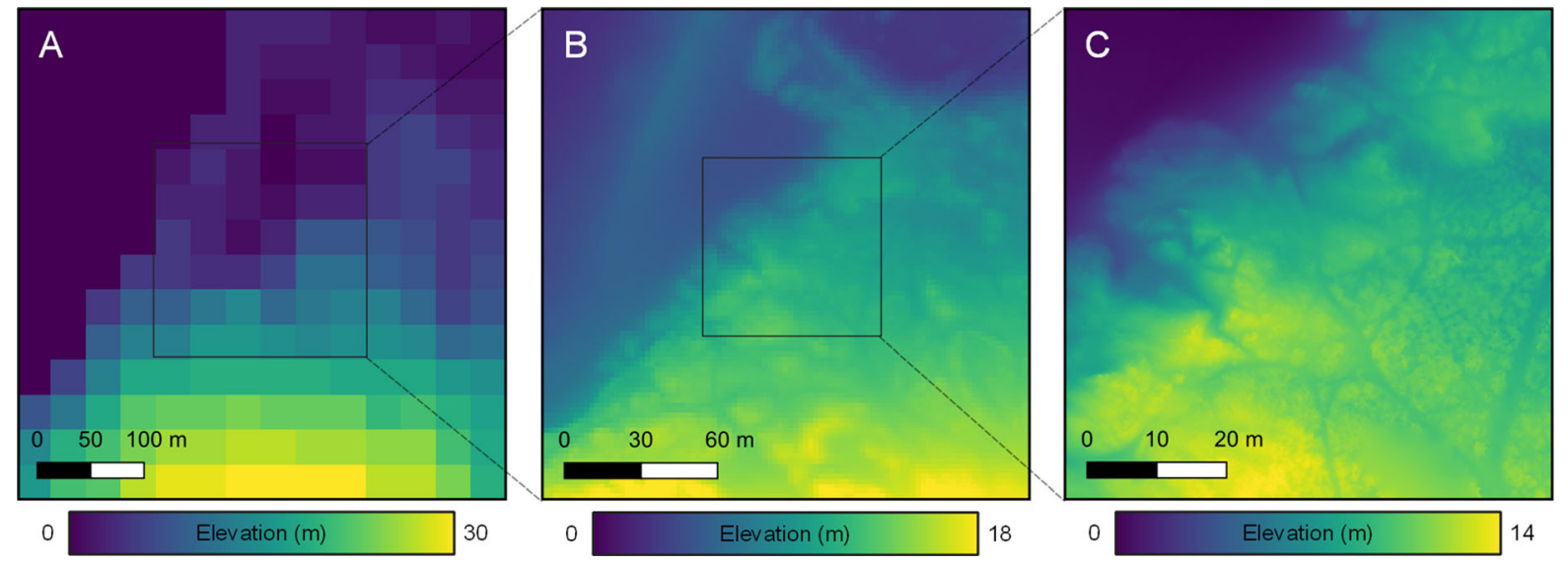

Fig. 1 Comparison of elevation models at varying spatial resolution from different remote sensing platforms. $\mathbf{a} \sim 30 \mathrm{~m}$ spatial resolution digital surface model (DSM) data from the Shuttle Radar Topography Mission (SRTM; (van Zyl 2001). b $\sim 2 \mathrm{~m}$ spatial resolution DSM data from airborne LiDAR

some circumstances it is possible to discriminate 'ground' features from 'surface' features in areas absent of dense vegetation canopies (Anders et al. 2019). This is best performed on the dense point cloud, where points can be classified into two groups, and the resulting DTM can be constructed based on one of these groups. Alternatively, coarser spatial resolution LiDAR derived DTMs can be integrated if discrimination between ground and surface features is unfeasible (Meesuk et al. 2015). It is from this resulting DTM that slope, aspect, horizon angle and sky view can be calculated, by using widely available geospatial software tools.

Coarser grained satellite and airborne derived elevation products have routinely been used in microclimate models to calculate slope and aspect (e.g. Weiss and Weiss 1998; Moeslund et al. 2013) and wind sheltering effects (Lapen and Martz 1993). Sometimes the coarse spatial scale of these products, masks the topographic heterogeneity of a landscape, in both space and time. In contrast, drones provide the opportunity to capture data at user-dictated times, unlocking the ability to measure variation in landscapes over time due to natural (e.g. landslide; Seier et al. 2018) or human-induced (e.g. removal of crops; Holman et al. 2016) processes. Drone-derived topographic data also afford unprecedented opportunities to model microclimate at scales relevant to even small organisms (Choi et al. 2019). surveys conducted by the UK Environment Agency. c $\sim 18 \mathrm{~mm}$ spatial resolution DSM derived with optical data from a consumer grade camera on-board a 3DR Solo drone. Site location near Gwithian, Cornwall, UK (- 5.392059, $50.226993)$

\section{Canopy height}

Canopy height has an important bearing on microclimate in several respects. Firstly, when below canopy, but above ground estimates of microclimatic conditions are needed, it informs the extent to which radiation is attenuated for a given leaf area at any given height, as close to the top of the canopy, only a fraction of the total leaf area contributes to shading. Second, within the canopy, the scaling of leaf area to leaf spacing (a key determinant of within-canopy heat exchange (Goudriaan 1977), is ultimately determined by vegetation height. Also, the surface roughness parameters that govern temperature and wind profiles are difficult to measure directly, but reasonable empirical relationships between these and canopy height exist (Maki 1975; Shaw and Pereira 1982). Different formulae are used depending on leaf-shape, but the general principles in terms of relationship with leaf area apply. Goudriaan (1977) provides a comprehensive overview of this along with the relevant formulae.

A canopy height model can be acquired from SfMMVS datasets, depending on the density of the plant material, and the availability of ancillary datasets, such as LiDAR terrain models. If well-distributed 'true ground' points are absent in a given point cloud (i.e. when the surface expression is dominated by vegetation), it can be difficult to correctly separate the canopy from the underlying ground. When these 

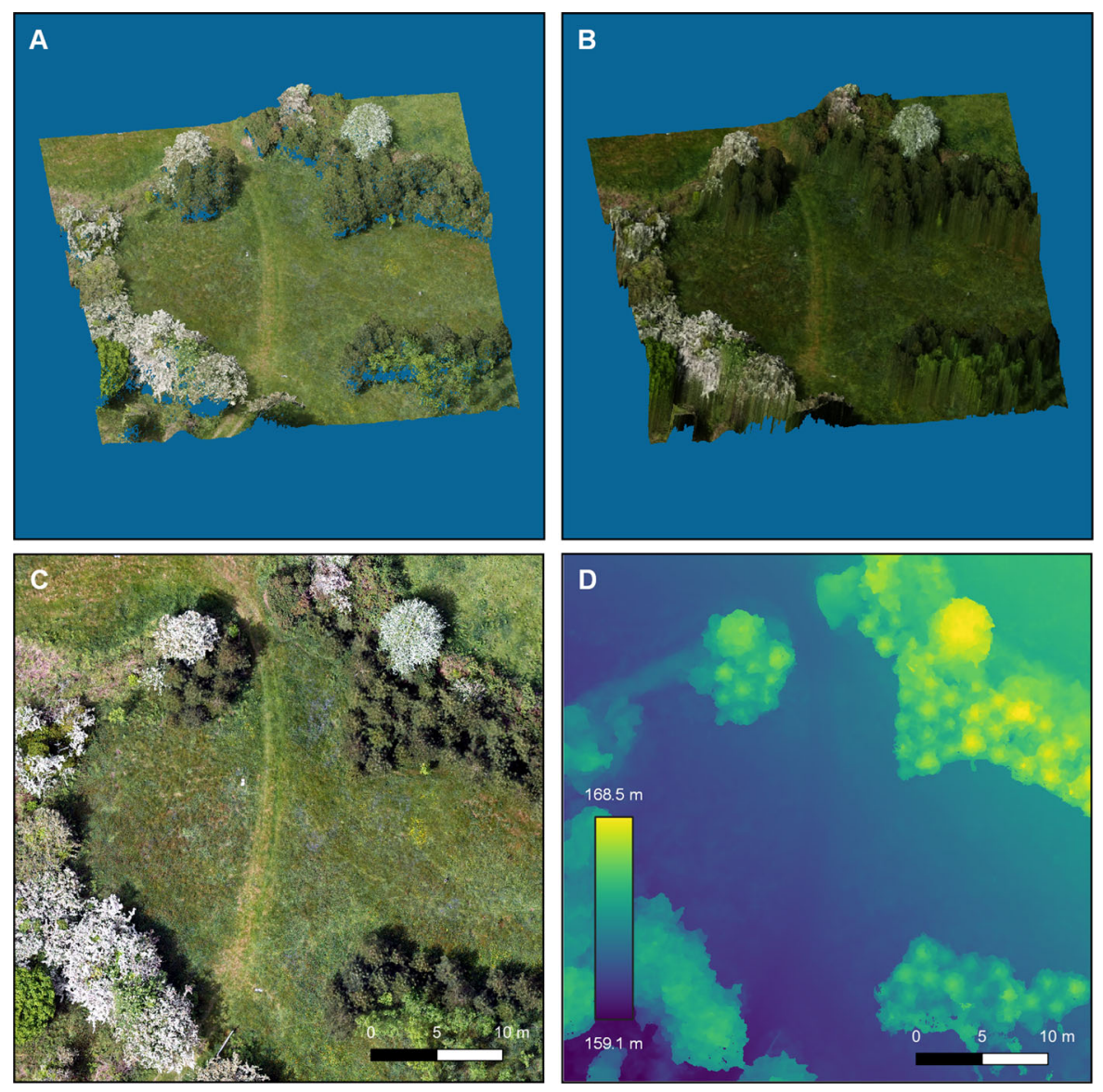

Fig. 2 Four example outputs from SfM-MVS processing of images captured from a Ricoh GR II consumer grade camera onboard a 3DR Solo multirotor drone, flying at $50 \mathrm{~m}$ altitude. Images processed and spatial products produced with Agisoft Metashape (Agisoft 2020). A dense point cloud, consisting of points georeferenced in $3 \mathrm{D}$ space, each with associated red,

points are visible, or complimentary data describing the ground are available, an effective subtraction of the DSM from the DTM can produce measurements of canopy height. Canopy height models of forest stands have been successfully created using a combination of SfM-MVS outputs (Fig. 3) and airborne LiDAR data (Lisein et al. 2013). Such data fusion has been used to track the change in canopy height over several months in grasslands (Borra-Serrano et al. 2019), and to measure crop heights in barley plots (Bendig et al. 2015). The reliance on complimentary ground or airborne LiDAR data for computing canopy heights in dense canopies may soon be reduced. Miniaturised LiDAR sensors suitable as payloads for drones are now emerging, opening opportunities for data capture green and blue (RGB) values. B a mesh, created using the dense point cloud. C a $15 \mathrm{~mm}$ spatial resolution georeferenced orthomosaic. D a $28 \mathrm{~mm}$ spatial resolution DSM, with elevation values above sea level displayed. Site location near Stithians, Cornwall, UK ( - 5.204639, 50.202037)

through canopies at fine spatial and temporal resolutions (Dash et al. 2019). However, this technology is only accessible to those with large budgets (miniaturised LiDAR systems cost approximately 10-100 times more than a hobbyist drone equipped with an optical camera). The ability to penetrate the canopy with drone-based LiDAR overcomes one of the shortfalls of SfM-MVS, which is the lack of subcanopy structural information in resultant datasets. Canopy structure plays a key role in influencing the temperatures close to the Earth's surface, and the ability to quantify height variation at fine spatial resolution will allow measurement of microclimate with a more realistic reflection of the natural environment. 

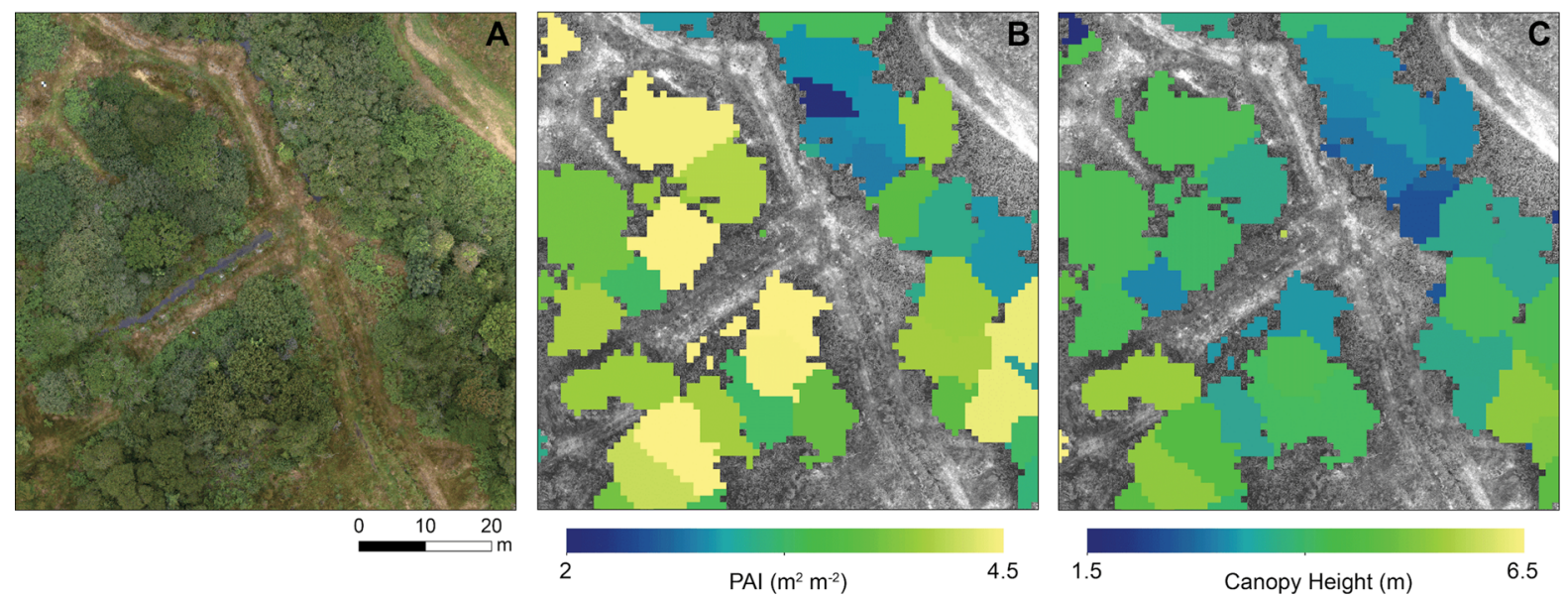

Fig. 3 Using SfM-MVS and multispectral data (Parrot Sequoia) to characterise heterogeneous environments and assign vegetation parameters. A a $20 \mathrm{~mm}$ spatial resolution georeferenced orthomosaic. $\mathbf{D}$ and $\mathbf{C} 1 \mathrm{~m}$ spatial resolution raster maps of overstorey vegetation plots displaying $\mathbf{B}$ plant area index

\section{Reflected shortwave radiation}

The amount of radiation absorbed by the ground surface and by vegetation, and hence the extent to which sunlight heats these surfaces, depends on their reflectance in different wavelengths. In static weather station configurations, pyranometers are typically used to measure changes in shortwave radiation over time. Combining upward and downward facing pyranometers and obtaining simultaneous measurements allows for the calculation of albedo (the weighted broad waveband reflectance in the shortwave spectrum). Ryan et al. (2017) have shown that miniaturised versions of such equipment can be deployed on lightweight drones to capture simultaneous upward and downward facing measurements of shortwave reflectance over relatively small spatial extents. A similar system, utilising a static upward facing pyranometer and a roaming downward facing device has been demonstrated by Levy et al. (2018), who successfully estimated heterogeneity in reflectance in deciduous hardwood forests. Cao et al. (2018) show that a consumer grade optical camera provides reasonable estimates of reflectance in visible wavelengths, but not in shortwave wavelengths, which require a multi-spectral camera. The positioning of the drone mounted sensor (i.e. nadir or oblique) will also influence measurements due to bi-directional reflectance factors. For microclimate modelling, both
(PAI) derived using an empirical model based on multispectral data and field measurements and $\mathbf{C}$ canopy height of overstorey vegetation plots derived from SfM-MVS data. Site location near Stithians, Cornwall, UK ( $-5.205158,50.201545)$. Data are author's own

ground and canopy reflectance are important, and in contrast to other platforms drones excel at differentiating between the two. Lastly, user-dictated visit times mean that changes in canopy colour (i.e. "greening"), which in turn influence reflectance, can be quantified through time and at fine temporal resolutions (Hoffmann et al. 2016).

\section{Leaf and plant area}

The degree of canopy shading, wind profiles and evapotranspiration are strongly affected by canopy density and cover. The amount of sunlight penetrating the canopy, for example, is often described using equations similar to Beer's law in which radiation transmission through the canopy is inversely related to the total one-sided leaf area per unit ground area (Campbell and Norman 1998). Similar relationships have been defined for wind profiles, whereby speed is attenuated as a function of the spacing of leaves, and hence the density of leaves (e.g. Inoue and Uchijima 1979). Much of the early ground-breaking theoretical work on the influence of canopy density on microclimate assumes that canopies are homogeneous or can be described using a small number of parameters that indicate variance. The spatially explicit nature of canopy gaps, the influence of vertical structure on patterns of absorption and scattering of radiation, and variation in the translucence of leaves relative to 
woody vegetation is largely ignored. In reality, most vegetated ecosystems comprise both woody and plant material and are subject to disturbances such as fire, extreme winds and herbivore grazing (e.g. Chazdon 2003). The severity of these disturbances influence canopy closure, stand structure, regeneration dynamics and plant community composition such that canopies are highly heterogeneous in both time and space. Commonly used measures used to characterise vegetation are the leaf area index (LAI), the total onesided leaf area per unit ground area, and the plant area index (PAI), which encompasses all plant structures rather than just leaves.

While ground-based techniques such as the use of hemispherical photography (Zhao et al. 2019) or specialised scientific instrumentation such as the LiCOR LAI-2000 (Calders et al. 2018), can potentially be used to measure this heterogeneity, they are limited in their spatial extent, and in their ability to capture spatially explicit variation. Drone platforms offer an exciting though unproven means by which to bridge the gap between in situ measurement, and wider spatial coverage, compared to informative structural information provided by satellite data (Fig. 4). From a top-down perspective, satellitederived vegetation indices such as the Normalised Difference Vegetation Index (NDVI) work moderately well for estimating LAI values between 0 and 3 (Carlson and Ripley 1997) — the relationship, effectively a normalised ratio between red and NIR reflected light, is based on the fact that the differential between red absorption and NIR reflection is greatest when there are larger amounts of photosynthetic material present (Carlson and Ripley 1997). However, the presence of even a small proportion of bare ground as opposed to an even distribution of vegetation, may complicate the interpretation of multispectral data in deriving estimates of leaf area due to non-linearities in the processes that govern radiative transfer in different wavelengths (Sellers 1985). Multispectral sensors onboard a lightweight drone have been used to investigate the relationship between LAI and various NDVIderivative measures in structurally complex mangrove forests (Tian et al. 2017) and offer considerable advantage over satellite-based products in being able to quantify heterogeneity at fine spatial resolution (Fig. 3). Alternatively, vegetation indices such as the Excess Green Vegetation Index have also been utilised as a proxy for LAI (Liu and Wang 2018). This index does not require near-infrared data in its calculation and therefore provides a potentially cheaper sensor setup on the drone platform, though the theoretical basis for this relationship is not as well-established. Aside from purely multi-spectral measurements, LAI has been calculated from voxelised output from SfMMVS point data. A study on sweet potato plants showed that there was greater correlation between field and SfM-MVS derived LAI measures at lower LAI values $(<0.4)$ than higher (Teng et al. 2019). Novel approaches are being used to extract LAI from individual fine spatial resolution optical images, by utilising the viewing geometry of obliquely captured images (Roth et al. 2018), with multiple, welldistributed viewing angles providing more accurate LAI measurements compared to ground-based measures (Roosjen et al. 2018). This technique is particularly suited to drones, where viewing geometry can be calculated from on-board autopilot accelerometer measurements. Furthermore, pioneering work combining SfM-MVS outputs with bidirectional spectroscopy measurements to obtain LAI in salt marsh environments (Badura et al. 2019), shows that a modified chlorophyll absorption ratio index correlated well with LAI across differing plant densities. This is another example of how proxy spectral measurements can provide a means of acquiring information about the structure of vegetation from drone mounted sensors. Hemispherical photos from a drone platform have also been used to infer canopy structure and associated measures such as the one-sided area of both dead and live vegetation (Brüllhardt et al. 2020). This work also showed the power of multi-sensor approaches, combining SfM-MVS data with top-down hemispherical photos for rapid data acquisition at fine spatial and temporal scales. Time-series studies involving sensors mounted on drones require careful methodological design and consideration. For example, retrieval with the Parrot Sequoia multispectral camera can vary with illumination angle and flying height, showing that measurement variation may be introduced with the use of drones (Stow et al. 2019). Drones afford opportunities to map LAI values across space and time and identify canopy gaps, though reliable means of doing so are still in their infancy. This is an active area of research, in which further testing of different environments with varying vegetation characteristics will reveal the limits to such techniques. Saturation effects, due to the difficulty of 

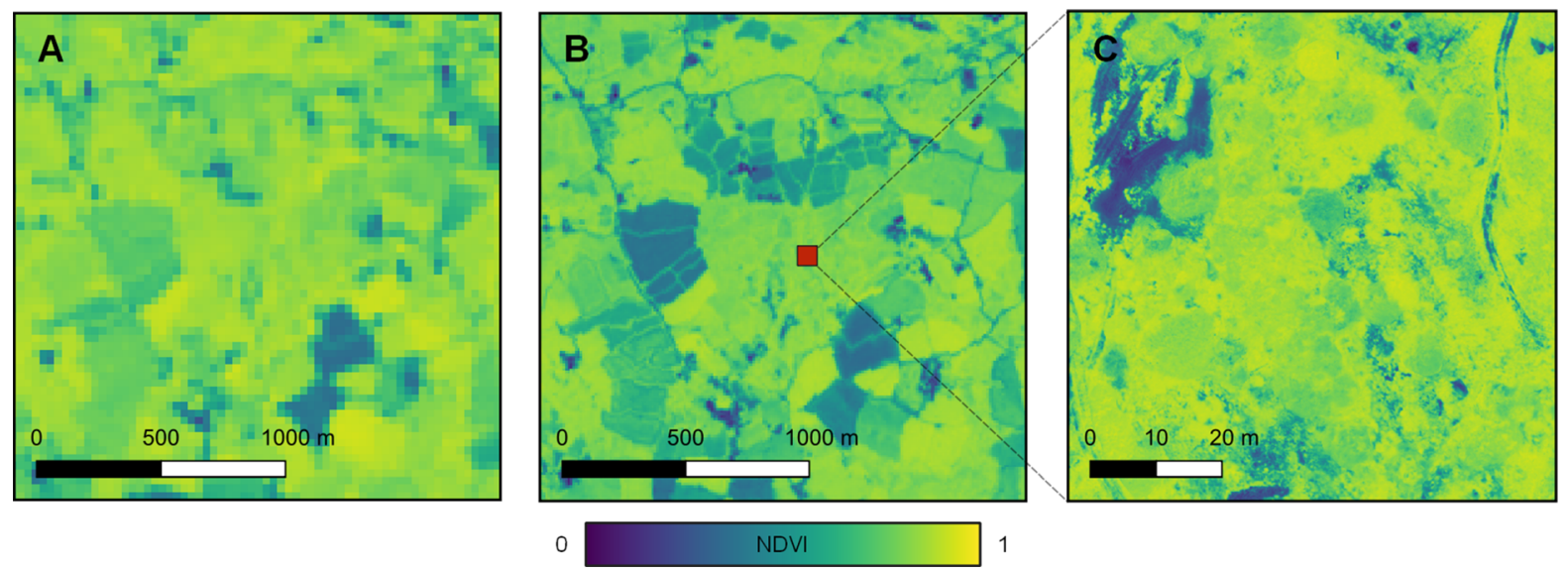

Fig. 4 Comparison of Normalised Difference Vegetation Index (NDVI) values at varying spatial resolution from different satellite and drone platforms. A $30 \mathrm{~m}$ spatial resolution data from the Landsat program, collected on 21/06/2019. B $15 \mathrm{~m}$ spatial resolution data from the Sentinel-2 program, collected on

acquiring optical data through dense canopies, can lead to erroneous measures of plant and leaf area. Drone mounted LiDAR sensors provide a potential solution in these situations, by acquiring structural information through whole canopies (Moeser et al. 2014).

Leaf size, structure and distribution angles

Leaf angles influence both the absorption of radiation and its transmission through the canopy, such that for vertically-orientated leaves, far less radiation penetrates the canopy when the sun is low above the horizon (Campbell and Norman 1998). Size and structure influence the patterns of air flow along the surface of a leaf, and hence how much heat is exchanged with the air (Grace and Wilson 1976). The size and shape of leaves also governs their spacing in relation to leaf area, which in turn affects the wind regimes within vegetated canopies. In consequence, all these parameters have a bearing on microclimatic conditions within the canopy. Much as in microclimate modelling more generally, methods exploring the measurement and acquisition of plant growth traits from data captured by drone-mounted sensors appears to be focussed on agricultural applications. Low-flying drones with on-board optical sensors make an ideal platform for field-based high-throughput phenotyping (Zhao et al. 2018), providing measurements of crop structure and size over larger spatial extents than
27/06/2019. C $80 \mathrm{~mm}$ spatial resolution data from a Parrot Sequoia multispectral sensor, on board a 3DR solo drone, collected on 21/06/2019. Site location near Stithians, Cornwall, UK (50.202037, - 5.204639)

ground-based observations. Kim et al. (2018) acquired predictive measures of leaf width $\&$ height (vegetation fractions and plant heights) from a combination of RGB spectral and SfM-MVS produced structural data. One such study outside of the agricultural realm, studied the measurement of leaf angle distributions from drones. McNeil et al. (2016) compared dronederived leaf angle distribution with ground basedmeasurements and showed that the two methods are comparable across several broadleaf tree species. Apart from these examples, published studies aiming to attain measures of leaf size, structure and distribution are in their infancy. Future work will require careful validation, and testing to investigate performance across different vegetation types.

\section{Photosynthetic capacity}

The photosynthetic capacity of leaves is strongly related to stomatal conductance, a key determinant of vapour loss from leaves, and hence the latent heat components in Eq. (1) (Table 1). Photosynthesis is stimulated by radiation in the same waveband as human vision, and this waveband is referred to as Photosynthetically Active Radiation (PAR). As a rule of thumb, the number of moles of carbon dioxide fixed in photosynthesis is closely proportional to the number of moles of photons absorbed in the PAR waveband, at least for low light levels. However, many developmental processes in green plants have been found to 
depend on the state of the pigment phytochrome which exists in two photo-interconvertible forms that absorb radiation in wavebands centred at $660 \mathrm{~nm}$ (red lightthe Pr form) and $730 \mathrm{~nm}$ (far-red light—-the Pfr form) (Kasperbauer 1987). In consequence, as for leaf area, NDVI has been used as a proxy measurement for photosynthetic capacity, for example with data from satellite platforms (Coops et al. 1998). However, as with estimating leaf area, this approach requires homogenous green vegetation cover, or further parameterisation describing heterogeneity in the vegetated canopy, to account for variation in vegetation greenness in space (Sellers 1985). Whilst NDVI is a widely used index for monitoring plant status such as biomass estimation, it is very generalised, suffers saturation issues in high biomass conditions, and it becomes difficult to differentiate between leaf area per se and the photosynthetic capacity per unit leaf area. However, reasonable models relating photosynthetic capacity to radiation transmission, and hence to leaf area have been developed (e.g. (Kelliher et al. 1995)). Other indices such as the Soil Adjusted Vegetation Index (SAVI) and the Enhanced Vegetation Index (EVI) have been developed to optimize the signal from vegetation, by accounting for atmospheric and soil background effects (Jiang et al. 2008). While such indices are useful for satellite derived data with relatively coarse spatial resolutions, the scales at which drone data are typically collected minimises the effects of atmosphere and soil background effects. More sophisticated methods, relying on more detailed spectral information are now available, and potentially, deployable on drones. Hyperspectral imaging sensors have been used to measure Chlorophyll $a+b$ and carotenoids (leaf pigments associated with photosynthesis) in vineyards (Zarco-Tejada et al. 2013). These measures offer a potential way to understand the photosynthetic capacity of leaves in a generalisable way that can potentially be scaled up to satellite metrics. Of particular relevance to microclimate studies are advancements in remote estimation of light use efficiency (LUE) and solar induced fluorescence in plants. Both can potentially/or already have been measured from drone platforms (Garzonio et al. 2017), although these approaches are not yet well established at the time of writing. One such example, in an agricultural setting, shows that drone-mounted modified consumer-grade RGB cameras (converted to capture NIR wavelengths) can be used to derive measures of absorbed photosynthetically active radiation (Tewes and Schellberg 2018). While promising, further work is required to understand how such measures of photosynthetic activity can be achieved in more heterogeneously vegetated scenarios.

\section{Direct micro-meteorological measurements from drones}

Whilst there are plentiful suggestions in the preceding sections for methods of integrating drone-scale data into microclimate research, there is also potential for direct measurements to be acquired from droneplatforms.

Understanding and quantifying the spatially variable wind environment near to the ground is challenging with other technologies-yet from drones this can be achieved relatively straightforwardly. Comprehensive microclimate models require hourly or sub-hourly wind speed and direction measurements as inputs. Typically, these data are available from sensors at fixed locations (e.g. land surface observations in the MIDAS dataset (Met Office 2012)) or historically as modelled values (often at coarse spatial resolution; e.g. ERA5 global climate dataset (Copernicus Climate Change Service 2017). Obtaining near real-time, spatially explicit measurements with sensors on-board drone platforms enables precise quantification of the conditions that influence temperatures within and beneath the canopy (Fig. 5). Such data could improve the ways in which wind speed and direction are influenced by terrain and the environmental structures. Already, drones have been used to quantify wind parameters, including the degree of turbulence above ground. Specifically, wind speed and direction have been estimated both directly with an anemometer mounted on a lightweight hexacopter (e.g. Fig. 5), and indirectly, utilising attitude information from inertial measurement unit (IMU) sensors within the drone autopilot (Palomaki et al. 2017), and modified turbulence and temperature sensors on-board a fixed wing platform (Lawrence and Balsley 2013). Another such application could be to use video and image analysis techniques to understand how wind changes the shape and size of vegetation canopies on fine temporal scales, and the degree of wind fraction. The motion of broadleaf trees in the wind has been modelled using 3D tree models derived from TLS data (Jackson et al. 
2019), and a comparison or combination with dronederived data is a potential avenue of research.

While much scientific research focuses on the use of optical sensors, there is also potential for drones to make in situ measurements with alternative sensors, for example to measure air temperature and humidity. Such approaches have been demonstrated with the measurement of water temperature (Sørensen et al. 2017), air temperature in vertical profiles from ground level to $~ 1000 \mathrm{~m}$ a.g.l (Cassano 2014), and air temperature using recorded sound (Finn et al. 2019). Techniques such as these could be particularly valuable in topographically challenging and/or inaccessible environments (e.g. coastal or mountainous settings), where obtaining in situ measurements would be challenging. Lightweight drone platforms also offer potential for the deployment of in situ sensors for longer-term data acquisition. Measurement devices such as temperature loggers could be deployed with high positional accuracy, in a similar way that has been demonstrated with GPS tracking devices on icebergs (McGill et al. 2011). Furthermore, remote download of data from loggers in outlying areas could also be utilised (Fig. 5). This technique is already being applied in wildlife research, where physically obtaining data from loggers is not a feasible option (especially on a regular basis; Cao et al. 2017).

Lastly, thermal infrared cameras can be used to measure the thermal infrared energy emitted by a given object. If the user knows the emissivity of the object(s) they are imaging, a temperature estimation can be made. In the natural environment, emissivity varies by only small amounts (i.e. $0.97-0.98$ for plants (Chen 2015) and 0.93-0.96 for soil (Campbell and Norman 1998). Therefore, if required, constrained estimations of emissivity can be made, with little chance of introducing much error into the measurements. As with many areas of research involving drones, we expect continued innovation in their use to measure environmental variables that are pertinent to microclimate modelling.

\section{Incorporating drone-scale observations into models of radiative transfer}

In most instances, variation in the radiation regime is the primary determinant of variation in microclimatic conditions. However, most microclimate models make spatially implicit assumptions about very fine-scale heterogeneity in vegetation characteristics, particularly in vertical structure. So rather than explicitly trying to quantify the position of every leaf within a canopy in order to determine the absorption, reflection and scattering of radiation, simple metrics such as leaf area, leaf-angle distributions and clumpiness metrics are used to model the behaviour of radiation implicitly. There is great potential to use processed drone-

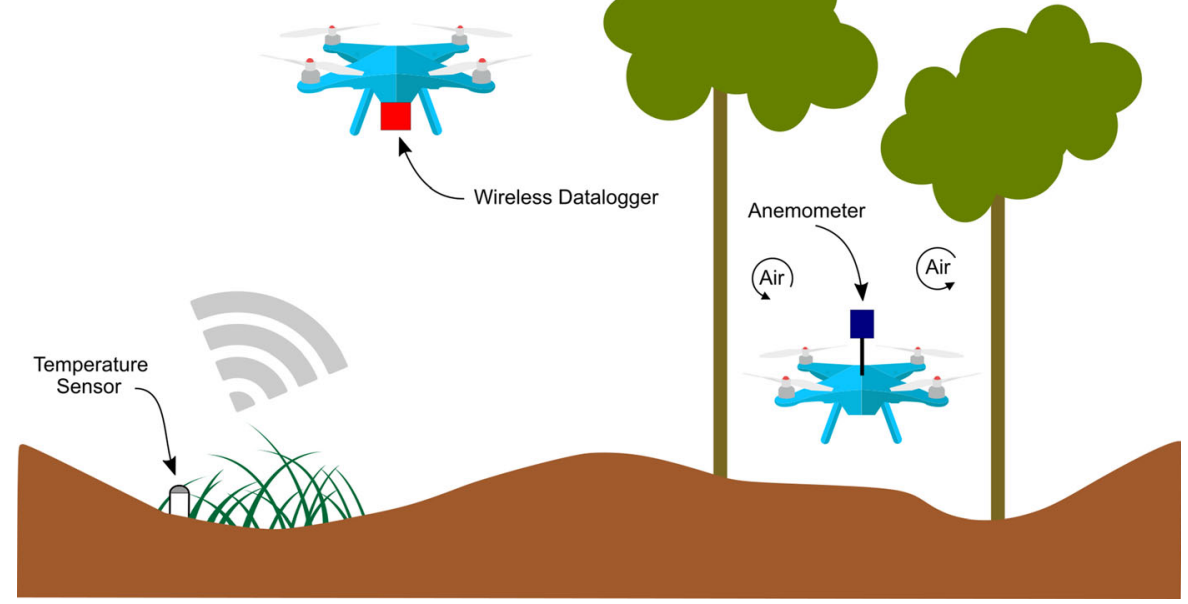

Fig. 5 Two novel ways drones could be used to collect environmental data relevant to microclimate modelling. Drones with remote download capability could collect data from deployed sensors. Also, drones can be mounted with equipment to measure wind speed and direction, in this case below the canopy. Drone icon from www.vecteezy.com 
derived data as inputs to $3 \mathrm{D}$ radiative transfer models. Doing so would afford the opportunity to model spatial heterogeneity in microclimate explicitly by providing fine spatial resolution representations of the environment in multiple dimensions. Radiative Transfer (RT) modelling is novel in the context of microclimate modelling research, yet is relatively welldeveloped in the broader field of remote sensing as it is used to infer how vegetation structure influences the electromagnetic signals detected by satellites. The ingestion of drone-scale data into such models would represent a new step that could benefit both fields of research.

RT models vary in complexity from basic turbid medium models (e.g. PROSAIL; Jacquemoud et al. 2009) to fully three dimensional models (e.g. Discrete Anisotropic Radiative Transfer (DART; GastelluEtchegorry et al. 2015) and FLIGHT (North 1996)). Their utility to microclimate research lies in the reversal of the approaches normally used to understand satellite signals (i.e. instead of being used to understand the behaviour of reflected radiation they are instead used to infer incoming solar radiation). Drone-derived datasets can dovetail with existing RT model architecture to explore how fine-scale spatial and structural variation in the environment can affect solar radiative transfer budgets. Drone-derived products which allow fine-scaled parameterisation of these models include SfM-MVS derived DTMs and canopy height models, in turn resulting in a realistic representation of the scene geometry. Besides canopy volume, leaf area index within the canopy may be acquired from multispectral data (Wang et al. 2005; Yao et al. 2017) and smaller canopy gaps may be quantified on the basis of fine spatial resolution RGB orthomosaics (Getzin et al. 2014).

To illustrate the potential utility of RT models, we provide an example where the 3D RT model DART was parameterised using fine-grained observations of canopy structure and reflectance captured from a drone (Fig. 6). A photogrammetric point cloud (Fig. 6b) was used to describe canopy geometry while LAI was derived from an empirical relationship between drone acquired NDVI image data and in situ hemispherical photography. The model produces a 3D radiative budget product from which the interception, transmission and absorption of radiation within the canopy and on surfaces can be extracted (Fig. 6c).
Further structural properties such as canopy layering, clumping, branch structure and leaf angular distribution which have considerable impact on light transmission require further assumptions or fieldbased measurements. Drone-derived LiDAR data promises major advances in this regard by providing datasets comparable to TLS which have been used to represent accurate canopies for 3D radiative transfer, though hardware, data acquisition and processing remains more expensive both financially and computationally (Mlambo et al. 2017).

$3 \mathrm{D}$ radiative transfer through a vegetated scene represented in all its complexities remains a computationally intensive process and therefore unsuitable for the operational modelling of the radiation microclimate. Opportunities lie instead in using outputs for validating simpler models and identifying the key drivers of small scale variability to improve model assumptions.

\section{Conclusions}

Comprehensive microclimate modelling requires understanding and measurement of a suite of environmental parameters (Table 1). Often, existing remote sensing datasets, from satellite, airborne or groundbased platforms offer usable data, but commonly at coarser resolutions than is desirable or mismatched in time. Proximal sensing technologies such as drones offer the opportunity for more scale-appropriate measurements, in turn providing a more realistic representation of the natural environment. Such nuanced differences in the structure of the natural environment and the meteorological conditions can strongly influence the temperatures experienced near the Earth's surface. This paper explores the way in which drone-data can be used to acquire such environmental parameters, and how one makes the transition from raw drone-derived data, to useful estimates of microclimatic conditions. While the acquisition of data relating to some parameters is more achievable than others, there is no doubt this is an exciting time for research involving microclimate. Drones are a democratising technology, with great flexibility in where and when data are captured (Table 2). They present an opportunity to bridge the scale-mismatches between existing remote sensing datasets and the processes governing temperature close to the ground 
A

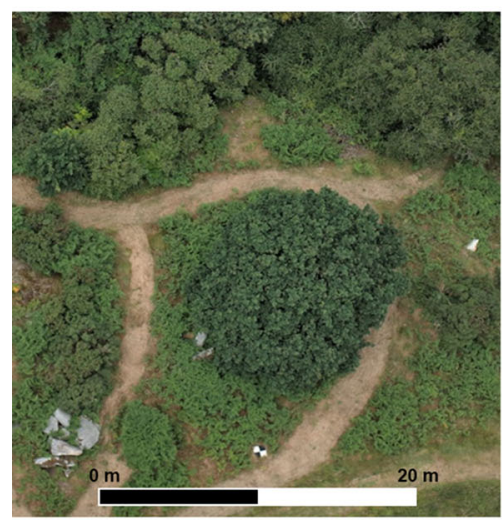

B

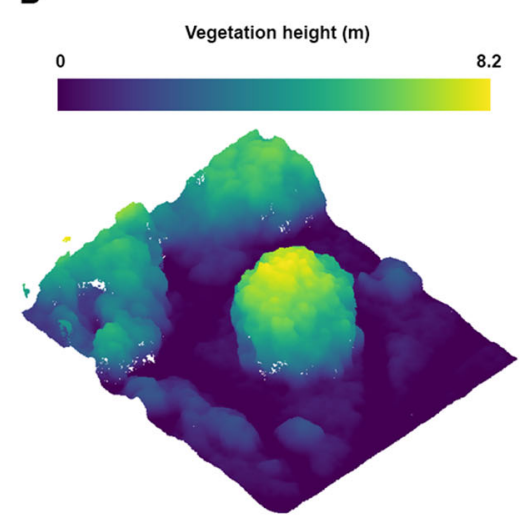

C

Intercepted shortwave radiation $\left(\log \mathrm{W} \mathrm{m}^{-2} \mu \mathrm{m}^{-1}\right)$

0

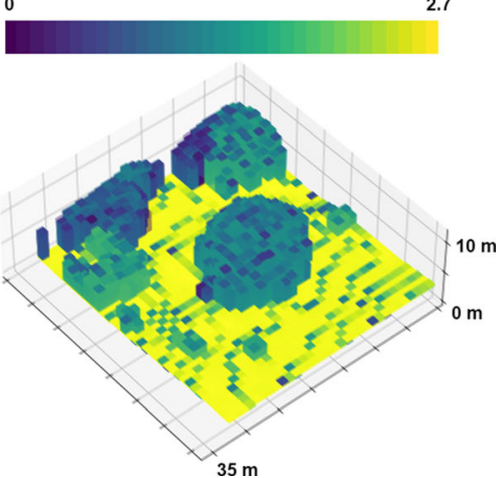

Fig. 6 Illustration of an approach to model radiative transfer of a vegetated scene based on a SfM-MVS dense point cloud. A Drone RGB image showing the modelled scene focused on an isolated oak tree. B Dense SfM-MVS point cloud of the scene, coloured by normalised point height over ground. C 3D radiative budget output from the DART model depicting the amount of shortwave radiation intercepted per cell (resolution: $1 \times 1 \times 0.25 \mathrm{~m})$. Model was run for 22nd of July at 12:00 BST assuming fully direct irradiance conditions

Table 2 A summary of the key advantages and limitations of using drone technology to collect data useful for microclimate modelling

\begin{tabular}{ll}
\hline Advantages & Limitations \\
\hline $\begin{array}{l}\text { Democratising-data collection in the hands of the researcher } \\
\text { interested in microclimate. Reduced reliance on large agencies }\end{array}$ & $\begin{array}{l}\text { Legislation-the rules and regulations surrounding drone } \\
\text { operations varies between countries, and can hinder the ability } \\
\text { for remote sensing data that is typically used for microclimate } \\
\text { modelling }\end{array}$ \\
$\begin{array}{l}\text { to operate in some areas. However, non-urban areas tend to be } \\
\text { more accessible and likely the focus of most microclimate } \\
\text { research }\end{array}$
\end{tabular}

Flexibility (design)—different sensors and instruments can be attached to a variety of airframe designs, allowing for a wide range of data to be collected

Flexibility (operation)—data collection can take place at userdictated times, and in response to environmental and ecological processes (e.g. bud burst)

Complimentary - drones can be used to collect data representative of the wider environment. Such data can then be combined with other remote sensing or in situ measurements. Furthermore, such data can be used in workflows such as radiative transfer modelling

Sensor cost-although some consumer grade sensors are easy to acquire and relatively affordable $(<£ 1000)$, some such as LiDAR are still very expensive, limiting access to such technology

Processing overheads - substantial time and computing resources can be required to process and analyse the fine-grained data typically collected with drones. This is especially the case at the fine spatial resolution scales relevant to microclimate modelling

Software costs - software used to process drone data (especially for SfM-MVS) can be prohibitively expensive, and sometimes more than the cost of a drone and sensor

(Milling et al. 2018). This is crucial when studying environmental and biological processes that vary at very fine scales (e.g. plant abscission or insect metamorphosis), and ultimately for understanding the temperatures that many organisms actually experience. Although data captured with drones will often be over limited spatial extents, they can provide insight into the heterogeneity of the wider landscape through the sampling of different environments.

Caution should be exercised with regards to the volume of data produced by drone-mounted sensors. Users must carefully consider the time and resources required for processing drone-derived data. For example, SfM-MVS workflows can take several days to 
complete for $<5$ ha. This is likely to become more of an issue as the availability of miniaturised sensors increases, and the ability to capture a fusion of data from several sensors in a single flight becomes a reality (Sankey et al. 2017). For those wishing to investigate microclimate over wide spatial extents, the best use of drone technology would be to sample the breadth of habitats and environments capturing variation in the vegetation and terrain parameters, in turn producing representative sets of parameters for such habitats or environments (Table 2). Furthermore, an approach integrating in situ measurements, with remote sensing data from multiple platforms could be used to infer fine-scale temperature differences over larger spatial extents than is achievable solely with field measures or drone data alone (Reichenau et al. 2016). Looking forward, a multiscale approach, utilising multiple remote sensing platforms (including fine scale data from drones) alongside field measurements (Alvarez-Vanhard et al. 2020) will likely be the most productive approach to microclimate modelling.

Acknowledgements The work was supported by funding from the Met Office Hadley Centre Climate Programme (HCCP) funded by BEIS and Defra through collaboration with Dr Deborah Hemming, who leads HCCP work on UK pest risk with Defra's Animal and Plant Health Team. Additional support was provided by the European Regional Development Fund Agri-tech Cornwall Programme. Dominic Fawcett received funding from the European Union's Horizon 2020 research and innovation programme under the Marie Skłodowska-Curie Grant Agreement No 721995. We would like to thank three anonymous reviewers and the editor for their suggestions which helped improve the manuscript. This study did not generate any new data.

Open Access This article is licensed under a Creative Commons Attribution 4.0 International License, which permits use, sharing, adaptation, distribution and reproduction in any medium or format, as long as you give appropriate credit to the original author(s) and the source, provide a link to the Creative Commons licence, and indicate if changes were made. The images or other third party material in this article are included in the article's Creative Commons licence, unless indicated otherwise in a credit line to the material. If material is not included in the article's Creative Commons licence and your intended use is not permitted by statutory regulation or exceeds the permitted use, you will need to obtain permission directly from the copyright holder. To view a copy of this licence, visit http://creativecommons.org/licenses/by/4.0/.

\section{References}

Agisoft (2020) Agisoft Metashape Professional (Version 1.5.5) Allen LH, Sinclair TR, Lemon ER (1976) Radiation and Microclimate Relationships in Multiple Cropping Systems. In: ASA Special Publication. American Society of Agronomy, Crop Science Society of America, and Soil Science Society of America

Alvarez-Vanhard E, Houet T, Mony C et al (2020) Can UAVs fill the gap between in situ surveys and satellites for habitat mapping? Remote Sens Environ 243:111780. https://doi. org/10.1016/j.rse.2020.111780

Anders N, Valente J, Masselink R, Keesstra S (2019) Comparing filtering techniques for removing vegetation from UAV-based photogrammetric point clouds. Drones 3:61. https://doi.org/10.3390/drones3030061

Anderson K, Westoby MJ, James MR (2019) Low-budget topographic surveying comes of age: structure from motion photogrammetry in geography and the geosciences. Prog Phys Geogr: Earth Environ 43:163-173. https://doi.org/10. 1177/0309133319837454

Badura GP, Bachmann CM, Tyler AC et al (2019) A novel approach for deriving LAI of salt marsh vegetation using structure from motion and multiangular spectra. IEEE J Sel Topics Appl Earth Obs Remote Sens 12:599-613. https:// doi.org/10.1109/JSTARS.2018.2889476

Bendig J, Yu K, Aasen $\mathrm{H}$ et al (2015) Combining UAV-based plant height from crop surface models, visible, and near infrared vegetation indices for biomass monitoring in barley. Int J Appl Earth Obs Geoinf 39:79-87. https://doi. org/10.1016/j.jag.2015.02.012

Bennie J, Huntley B, Wiltshire A et al (2008) Slope, aspect and climate: spatially explicit and implicit models of topographic microclimate in chalk grassland. Ecol Model 216:47-59. https://doi.org/10.1016/j.ecolmodel.2008.04. 010

Borra-Serrano I, Swaef TD, Muylle H et al (2019) Canopy height measurements and non-destructive biomass estimation of Lolium perenne swards using UAV imagery. Grass Forage Sci 74:356-369. https://doi.org/10.1111/gfs. 12439

Brüllhardt M, Rotach P, Schleppi P, Bugmann H (2020) Vertical light transmission profiles in structured mixed deciduous forest canopies assessed by UAV-based hemispherical photography and photogrammetric vegetation height models. Agric For Meteorol 281:107843. https://doi.org/ 10.1016/j.agrformet.2019.107843

Calders K, Origo N, Disney M et al (2018) Variability and bias in active and passive ground-based measurements of effective plant, wood and leaf area index. Agric For Meteorol 252:231-240. https://doi.org/10.1016/j. agrformet.2018.01.029

Campbell GS (1986) Extinction coefficients for radiation in plant canopies calculated using an ellipsoidal inclination angle distribution. Agric For Meteorol 36:317-321. https:// doi.org/10.1016/0168-1923(86)90010-9

Campbell GS, Norman J (1998) An introduction to environmental biophysics. Springer, Berlin

Cao H, Liu Y, Yue X, Zhu W (2017) Cloud-assisted UAV data collection for multiple emerging events in distributed 
WSNs. Sensors 17:1818. https://doi.org/10.3390/ s17081818

Cao C, Lee X, Muhlhausen J et al (2018) Measuring landscape albedo using unmanned aerial vehicles. Remote Sens 10:1812. https://doi.org/10.3390/rs10111812

Carlson TN, Ripley DA (1997) On the relation between NDVI, fractional vegetation cover, and leaf area index. Remote Sens Environ 62:241-252. https://doi.org/10.1016/S00344257(97)00104-1

Cassano JJ (2014) Observations of atmospheric boundary layer temperature profiles with a small unmanned aerial vehicle. Antarct Sci 26:205-213. https://doi.org/10.1017/ S0954102013000539

Chazdon RL (2003) Tropical forest recovery: legacies of human impact and natural disturbances. Perspect Plant Ecol Evol Syst 6:51-71. https://doi.org/10.1078/1433-8319-00042

Chen C (2015) Determining the leaf emissivity of three crops by infrared thermometry. Sensors 15:11387-11401. https:// doi.org/10.3390/s150511387

Choi F, Gouhier T, Lima F et al (2019) Mapping physiology: biophysical mechanisms define scales of climate change impacts. Conserv Physiol. https://doi.org/10.1093/ conphys/coz028

Coops NC, Waring RH, Landsberg JJ (1998) Assessing forest productivity in Australia and New Zealand using a physiologically-based model driven with averaged monthly weather data and satellite-derived estimates of canopy photosynthetic capacity. For Ecol Manag 104:113-127. https://doi.org/10.1016/S0378-1127(97)00248-X

Copernicus Climate Change Service (C3S) (2017) ERA5: fifth generation of ECMWF atmospheric reanalyses of the global climate. Copernicus Climate Change Service Climate Data Store (CDS)

Cowan IR (1972) Mass and heat transfer in laminar boundary layers with particular reference to assimilation and transpiration in leaves. Agric Meteorol 10:311-329. https:// doi.org/10.1016/0002-1571(72)90035-0

Dash JP, Watt MS, Paul TSH et al (2019) Early detection of invasive exotic trees using UAV and manned aircraft multispectral and LiDAR data. Remote Sens 11:1812. https://doi.org/10.3390/rs11151812

Duffy JP, Cunliffe AM, DeBell L et al (2018) Location, location, location: considerations when using lightweight drones in challenging environments. Remote Sens Ecol Conserv 4:7-19. https://doi.org/10.1002/rse2.58

Ehbrecht M, Schall P, Ammer C, Seidel D (2017) Quantifying stand structural complexity and its relationship with forest management, tree species diversity and microclimate. Agric For Meteorol 242:1-9. https://doi.org/10.1016/j. agrformet.2017.04.012

Faye E, Rebaudo F, Yánez-Cajo D et al (2016) A toolbox for studying thermal heterogeneity across spatial scales: from unmanned aerial vehicle imagery to landscape metrics. Methods Ecol Evol 7:437-446. https://doi.org/10.1111/ 2041-210X.12488

Finn A, Rogers K, Meade J et al (2019) Spatio-temporal observations of temperature and wind velocity using dronebased acoustic atmospheric tomography. J Acoust Soc Am 145:1903-1904. https://doi.org/10.1121/1.5101906
Finnigan JJ (1985) Turbulent transport in flexible plant canopies. The forest atmosphere interaction. Reidel, Dordrecht, pp 443-480

Finnigan J (2000) Turbulence in plant canopies. Annu Rev Fluid Mech 32:519-571. https://doi.org/10.1146/annurev.fluid. 32.1.519

Forsmoo J, Anderson K, Macleod CJA et al (2019) Structure from motion photogrammetry in ecology: does the choice of software matter? Ecol Evol. https://doi.org/10.1002/ ece 3.5443

Garzonio R, Di Mauro B, Colombo R, Cogliati S (2017) Surface reflectance and sun-induced fluorescence spectroscopy measurements using a small hyperspectral UAS. Remote Sens 9:472. https://doi.org/10.3390/rs9050472

Gastellu-Etchegorry J-P, Yin T, Lauret N et al (2015) Discrete Anisotropic Radiative Transfer (DART 5) for modeling airborne and satellite spectroradiometer and LIDAR acquisitions of natural and urban landscapes. Remote Sens 7:1667-1701. https://doi.org/10.3390/rs70201667

Getzin S, Nuske RS, Wiegand K (2014) Using Unmanned Aerial Vehicles (UAV) to quantify spatial gap patterns in forests. Remote Sens 6:6988-7004. https://doi.org/10.3390/ rs6086988

Goudriaan J (1977) Crop micrometeorology: a simulation study. Phd, Pudoc

Grace J, Wilson J (1976) The boundary layer over a populus leaf. J Exp Bot 27:231-241

Hay JE (1993) Calculating solar radiation for inclined surfaces: practical approaches. Renew Energy 3:373-380. https:// doi.org/10.1016/0960-1481(93)90104-O

Hoffmann H, Jensen R, Thomsen A et al (2016) Crop water stress maps for an entire growing season from visible and thermal UAV imagery. Biogeosciences 13:6545-6563. https://doi.org/10.5194/bg-13-6545-2016

Holman FH, Riche AB, Michalski A et al (2016) High throughput field phenotyping of wheat plant height and growth rate in field plot trials using UAV based remote sensing. Remote Sens 8:1031. https://doi.org/10.3390/ rs8121031

Inoue K, Uchijima Z (1979) Experimental study of microstructure of wind turbulence in rice and maize canopies. Bull Natl Inst Agric Sci Ser A Phys Stat, pp 1-88

Jackson T, Shenkin A, Wellpott A et al (2019) Finite element analysis of trees in the wind based on terrestrial laser scanning data. Agric For Meteorol 265:137-144. https:// doi.org/10.1016/j.agrformet.2018.11.014

Jacquemoud S, Verhoef W, Baret F et al (2009) PROSPECT + SAIL models: a review of use for vegetation characterization. Remote Sens Environ 113:S56-S66. https://doi.org/10.1016/j.rse.2008.01.026

Jiang Z, Huete AR, Didan K, Miura T (2008) Development of a two-band enhanced vegetation index without a blue band. Remote Sens Environ 112:3833-3845. https://doi.org/10. 1016/j.rse.2008.06.006

Kasperbauer MJ (1987) Far-red light reflection from green leaves and effects on phytochrome-mediated assimilate partitioning under field conditions. Plant Physiol 85:350-354. https://doi.org/10.1104/pp.85.2.350

Kearney MR, Porter WP (2017) NicheMapR — an R package for biophysical modelling: the microclimate model. Ecography 40:664-674. https://doi.org/10.1111/ecog.02360 
Kearney MR, Matzelle A, Helmuth B (2012) Biomechanics meets the ecological niche: the importance of temporal data resolution. J Exp Biol 215:922-933. https://doi.org/ 10.1242/jeb.059634

Kelliher FM, Leuning R, Raupach MR, Schulze E-D (1995) Maximum conductances for evaporation from global vegetation types. Agric For Meteorol 73:1-16. https://doi.org/ 10.1016/0168-1923(94)02178-M

Kim D-W, Yun HS, Jeong S-J et al (2018) Modeling and testing of growth status for chinese cabbage and white radish with UAV-based RGB imagery. Remote Sens 10:563. https:// doi.org/10.3390/rs10040563

Klosterman S, Richardson A (2017) Observing spring and fall phenology in a deciduous forest with aerial drone imagery. Sensors 17:2852. https://doi.org/10.3390/s17122852

Kucharik CJ, Norman JM, Gower ST (1999) Characterization of radiation regimes in nonrandom forest canopies: theory, measurements, and a simplified modeling approach. Tree Physiol 19:695-706. https://doi.org/10.1093/treephys/19. 11.695

Lapen DR, Martz LW (1993) The measurement of two simple topographic indices of wind sheltering-exposure from raster digital elevation models. Comput Geosci 19:769-779. https://doi.org/10.1016/00983004(93)90049-B

Lawrence DA, Balsley BB (2013) High-resolution atmospheric sensing of multiple atmospheric variables using the DataHawk small airborne measurement system. J Atmos Ocean Technol 30:2352-2366. https://doi.org/10.1175/JTECHD-12-00089.1

Lembrechts JJ, Lenoir J, Roth N et al (2019) Comparing temperature data sources for use in species distribution models: from in situ logging to remote sensing. Glob Ecol Biogeogr. https://doi.org/10.1111/geb.12974

Levy CR, Burakowski E, Richardson AD (2018) Novel measurements of fine-scale albedo: using a commercial quadcopter to measure radiation fluxes. Remote Sens 10:1303. https://doi.org/10.3390/rs10081303

Lisein J, Pierrot-Deseilligny M, Bonnet S, Lejeune P (2013) A photogrammetric workflow for the creation of a forest canopy height model from small unmanned aerial system imagery. Forests 4:922-944. https://doi.org/10.3390/ f4040922

Liu X, Wang L (2018) Feasibility of using consumer-grade unmanned aerial vehicles to estimate leaf area index in Mangrove forest. Remote Sens Lett 9:1040-1049. https:// doi.org/10.1080/2150704X.2018.1504339

MacHattie LB, McCormack RJ (1961) Forest microclimate: a topographic study in Ontario. J Ecol 49:301-323. https:// doi.org/10.2307/2257264

Maclean IMD, Mosedale JR, Bennie JJ (2019) Microclima: an R package for modelling meso- and microclimate. Methods Ecol Evol 10:280-290. https://doi.org/10.1111/2041210X.13093

Maki T (1975) Interrelationships between zero-plane displacement, aerodynamic roughness length and plant canopy height. J Agric Meteorol 31:7-15. https://doi.org/10.2480/ agrmet.31.7

McGill PR, Reisenbichler KR, Etchemendy SA et al (2011) Aerial surveys and tagging of free-drifting icebergs using an unmanned aerial vehicle (UAV). Deep Sea Res Part II 58:1318-1326. https://doi.org/10.1016/j.dsr2.2010.11.007

McNeil BE, Pisek J, Lepisk H, Flamenco EA (2016) Measuring leaf angle distribution in broadleaf canopies using UAVs. Agric For Meteorol 218-219:204-208. https://doi.org/10. 1016/j.agrformet.2015.12.058

Meesuk V, Vojinovic Z, Mynett AE, Abdullah AF (2015) Urban flood modelling combining top-view LiDAR data with ground-view SfM observations. Adv Water Resour 75:105-117. https://doi.org/10.1016/j.advwatres.2014.11. 008

Met Office (2012): Met Office Integrated Data Archive System (MIDAS) Land and Marine Surface Stations Data (1853current). NCAS British Atmospheric Data Centre, 13/10/ 2020 . http://catalogue.ceda.ac.uk/uuid/ 220a65615218d5c9cc9e4785a3234bd0

Milling CR, Rachlow JL, Olsoy PJ et al (2018) Habitat structure modifies microclimate: an approach for mapping fine-scale thermal refuge. Methods Ecol Evol 9:1648-1657. https:// doi.org/10.1111/2041-210X.13008

Mlambo R, Woodhouse IH, Gerard F, Anderson K (2017) Structure from motion (SfM) photogrammetry with drone data: a low cost method for monitoring greenhouse gas emissions from forests in developing countries. Forests 8:68. https://doi.org/10.3390/f8030068

Moeser D, Roubinek J, Schleppi P et al (2014) Canopy closure, LAI and radiation transfer from airborne LiDAR synthetic images. Agric For Meteorol 197:158-168. https://doi.org/ 10.1016/j.agrformet.2014.06.008

Moeslund JE, Arge L, Bøcher PK et al (2013) Topographically controlled soil moisture drives plant diversity patterns within grasslands. Biodivers Conserv 22:2151-2166. https://doi.org/10.1007/s10531-013-0442-3

Monin AS, Obukhov AM (1954) Basic laws of turbulent mixing in the surface layer of the atmosphere. Trudy geofiziceskiy institut AN SSSR 24:163-187

Monteith J, Unsworth M (1990) Principles of environmental physics: plants, animals and the atmosphere. Edward Arnold, London

Norman J (1982) Simulation of microclimates. In: Biometeorology in integrated pest management. Academic Press, New York

North PRJ (1996) Three-dimensional forest light interaction model using a Monte Carlo method. IEEE Trans Geosci Remote Sens 34:946-956. https://doi.org/10.1109/36. 508411

Palomaki RT, Rose NT, van den Bossche M et al (2017) Wind estimation in the lower atmosphere using multirotor aircraft. J Atmos Ocean Technol 34:1183-1191. https://doi. org/10.1175/JTECH-D-16-0177.1

Pettorelli N, Nagendra H, Williams R et al (2015) A new platform to support research at the interface of remote sensing, ecology and conservation. Remote Sens Ecol Conserv 1:1-3. https://doi.org/10.1002/rse2.1

Pincebourde S, Murdock CC, Vickers M, Sears MW (2016) Fine-scale microclimatic variation can shape the responses of organisms to global change in both natural and urban environments. Integr Comp Biol 56:45-61. https://doi.org/ 10.1093/icb/icw016 
Potter KA, Woods HA, Pincebourde S (2013) Microclimatic challenges in global change biology. Glob Change Biol 19:2932-2939. https://doi.org/10.1111/gcb.12257

Raupach MR (1989) A practical Lagrangian method for relating scalar concentrations to source distributions in vegetation canopies. Q J R Meteorol Soc 115:609-632. https://doi. org/10.1002/qj.49711548710

Raupach MR, Finnigan JJ, Brunei Y (1996) Coherent eddies and turbulence in vegetation canopies: the mixing-layer analogy. Bound-Layer Meteorol 78:351-382. https://doi.org/ 10.1007/BF00120941

Reichenau TG, Korres W, Montzka C et al (2016) Spatial heterogeneity of leaf area index (LAI) and its temporal course on arable land: combining field measurements, remote sensing and simulation in a comprehensive data analysis approach (CDAA). PLoS ONE 11:e0158451. https://doi.org/10.1371/journal.pone.0158451

Richardson LF (1922) Weather prediction by numerical process. Cambridge University Press, Cambridge

Roosjen PPJ, Brede B, Suomalainen JM et al (2018) Improved estimation of leaf area index and leaf chlorophyll content of a potato crop using multi-angle spectral data-potential of unmanned aerial vehicle imagery. Int J Appl Earth Obs Geoinf 66:14-26. https://doi.org/10.1016/j.jag.2017.10. 012

Roth L, Aasen H, Walter A, Liebisch F (2018) Extracting leaf area index using viewing geometry effects-a new perspective on high-resolution unmanned aerial system photography. ISPRS J Photogramm Remote Sens 141:161-175. https://doi.org/10.1016/j.isprsjprs.2018.04. 012

Ryan JC, Hubbard A, Box JE et al (2017) Derivation of high spatial resolution albedo from UAV digital imagery: application over the greenland ice sheet. Front Earth Sci. https://doi.org/10.3389/feart.2017.00040

Sankey T, Donager J, McVay J, Sankey JB (2017) UAV lidar and hyperspectral fusion for forest monitoring in the southwestern USA. Remote Sens Environ 195:30-43. https://doi.org/10.1016/j.rse.2017.04.007

Seier G, Sulzer W, Lindbichler P et al (2018) Contribution of UAS to the monitoring at the Lärchberg-Galgenwald landslide (Austria). Int J Remote Sens 39:5522-5549. https://doi.org/10.1080/01431161.2018.1454627

Sellers PJ (1985) Canopy reflectance, photosynthesis and transpiration. Int J Remote Sens 6:1335-1372. https://doi.org/ 10.1080/01431168508948283

Shaw RH, Pereira AR (1982) Aerodynamic roughness of a plant canopy: a numerical experiment. Agric Meteorol 26:51-65. https://doi.org/10.1016/0002-1571(82)90057-7

Smith MW, Carrivick JL, Quincey DJ (2016) Structure from motion photogrammetry in physical geography. Prog Phys Geogr: Earth Environ 40:247-275. https://doi.org/10.1177/ 0309133315615805

Sørensen L, Jacobsen L, Hansen J (2017) Low cost and flexible UAV deployment of sensors. Sensors 17:154. https://doi. org/10.3390/s17010154

Stokes VJ, Morecroft MD, Morison JIL (2006) Boundary layer conductance for contrasting leaf shapes in a deciduous broadleaved forest canopy. Agric For Meteorol 139:40-54. https://doi.org/10.1016/j.agrformet.2006.05.011
Stow D, Nichol CJ, Wade T et al (2019) Illumination geometry and flying height influence surface reflectance and NDVI derived from multispectral UAS imagery. Drones 3:55. https://doi.org/10.3390/drones3030055

Suggitt AJ, Wilson RJ, Isaac NJB et al (2018) Extinction risk from climate change is reduced by microclimatic buffering. Nat Clim Change 8:713-717. https://doi.org/10.1038/ s41558-018-0231-9

Teng P, Ono E, Zhang Y et al (2019) Estimation of ground surface and accuracy assessments of growth parameters for a sweet potato community in ridge cultivation. Remote Sens 11:1487. https://doi.org/10.3390/rs11121487

Tewes A, Schellberg J (2018) Towards remote estimation of radiation use efficiency in maize using UAV-based lowcost camera imagery. Agronomy 8:16. https://doi.org/10. 3390/agronomy8020016

Tian J, Wang L, Li X et al (2017) Comparison of UAV and WorldView-2 imagery for mapping leaf area index of mangrove forest. Int J Appl Earth Obs Geoinf 61:22-31. https://doi.org/10.1016/j.jag.2017.05.002

Tucci G, Parisi E, Castelli G et al (2019) Multi-sensor UAV application for thermal analysis on a dry-stone terraced vineyard in rural tuscany landscape. ISPRS Int J Geo-Inf 8:87. https://doi.org/10.3390/ijgi8020087

van Zyl JJ (2001) The Shuttle Radar Topography Mission (SRTM): a breakthrough in remote sensing of topography. Acta Astronaut 48:559-565. https://doi.org/10.1016/ S0094-5765(01)00020-0

Vierling KT, Vierling LA, Gould WA et al (2008) Lidar: shedding new light on habitat characterization and modeling. Front Ecol Environ 6:90-98. https://doi.org/10.1890/ 070001

Wang Q, Adiku S, Tenhunen J, Granier A (2005) On the relationship of NDVI with leaf area index in a deciduous forest site. Remote Sens Environ 94:244-255. https://doi.org/10. 1016/j.rse.2004.10.006

Webster C, Westoby M, Rutter N, Jonas T (2018) Three-dimensional thermal characterization of forest canopies using UAV photogrammetry. Remote Sens Environ 209:835-847. https://doi.org/10.1016/j.rse.2017.09.033

Weiss SB, Weiss AD (1998) Landscape-level phenology of a threatened butterfly: a GIS-based modeling approach. Ecosystems 1:299-309. https://doi.org/10.1007/ s100219900023

Winstral A, Marks D, Gurney R (2009) An efficient method for distributing wind speeds over heterogeneous terrain. Hydrol Process 23:2526-2535. https://doi.org/10.1002/ hyp. 7141

Wong SC, Cowan IR, Farquhar GD (1979) Stomatal conductance correlates with photosynthetic capacity. Nature 282:424-426. https://doi.org/10.1038/282424a0

Yao X, Wang N, Liu Y et al (2017) Estimation of wheat LAI at middle to high levels using unmanned aerial vehicle narrowband multispectral imagery. Remote Sens 9:1304. https://doi.org/10.3390/rs9121304

Zarco-Tejada PJ, Guillén-Climent ML, Hernández-Clemente R et al (2013) Estimating leaf carotenoid content in vineyards using high resolution hyperspectral imagery acquired from an unmanned aerial vehicle (UAV). Agric For Meteorol 171-172:281-294. https://doi.org/10.1016/j.agrformet. 2012.12.013 
Zellweger F, De Frenne P, Lenoir J et al (2019) Advances in microclimate ecology arising from remote sensing. Trends Ecol Evol 34:327-341. https://doi.org/10.1016/j.tree.2018. 12.012

Zhao B, Zhang J, Yang C et al (2018) Rapeseed seedling stand counting and seeding performance evaluation at two early growth stages based on unmanned aerial vehicle imagery. Front Plant Sci. https://doi.org/10.3389/fpls.2018.01362

Zhao K, Ryu Y, Hu T et al (2019) How to better estimate leaf area index and leaf angle distribution from digital hemispherical photography? Switching to a binary nonlinear regression paradigm. Methods Ecol Evol 10:1864-1874. https://doi.org/10.1111/2041-210X.13273

Publisher's Note Springer Nature remains neutral with regard to jurisdictional claims in published maps and institutional affiliations. 